\title{
Assessment of Bacteriological Quality of Fast Foods and Soft Drinks in Relation to Safety and Hygiene
}

\author{
Jafor Ahmed ${ }^{1}$, M Lokman Hossain ${ }^{1}$, M Abdul Malek ${ }^{2}$ and Fauzia Begum ${ }^{1}$ \\ ${ }^{1}$ Food Microbiology Section, Institute of Food Science \& Technology (IFST), Bangladesh Council of Scientific \& Industrial Research (BCSIR), \\ Dr Qudrat-e-Khuda Road, Dhaka 1205, Bangladesh, ${ }^{2}$ Department of Microbiology, University of Dhaka, Dhaka 1000, Bangladesh
}

[Received 20 November 2007; Accepted 14 June 2008]

\begin{abstract}
Bacteriological quality assessment of fast foods and soft drinks of different establishments of Dhaka City was carried out. For systematic study of varieties of such foods consumed by different class of people, the food samples were divided into four major categories: Type A (upper class), Type B (middle class), Type C (moderate class) and Type $\mathrm{D}$ (lower class). The quality of samples was assessed by determining standard plate count (SPC). The SPC showed that about $15 \%$ of Type A, $23 \%$ of Type B, $43 \%$ of Type C and $57 \%$ of Type D samples were unsafe for human consumption. Coliform bacteria were detected in about $13-48 \%$ of various food varieties. Psychrophilic bacteria were present in about $19-42 \%$ samples, indicating not suitable for longterm preservation in refrigeration condition. One sample of Type A and two samples each of Type B, Type C and Type D yielded growth of Salmonella and a considerable number of the samples contained Escherichia coli. In this study it was found that the condition of most of the Type $C$ and Type $D$ food and drinks were unsafe for consumption. The safely and hygienic status of Type A and Type B were comparatively better than those of Type $C$ and Type $D$.
\end{abstract}

Keywords: Bacteriological quality, Fast food, Soft drink, Safety, Hygiene

Food and drinks with proper nutritional value, hygienic in quality and appropriate in quantity is essential for good and active life. Fast foods, ready-to-eat are gradually getting popularity and hence, a huge number of fast food shops are growing even without concerning of microbial safety and hygiene ${ }^{1}$. The recent trends in eating out among upper society, teenagers and youth have also increased and the fast food has won the palate of those groups. These are served as helpful purpose in official and private meeting, working people at lunch time and also Tiffin of students of different categories etc. But those fast foods may cause of serious problem when they are contaminated with pathogenic microorganisms due to lack of proper environmental and sanitary processing, lack of proper hygienic practices and storage mishandling².

The disease causing agents spread by food and water not only incapacitate large groups of people, but also sometimes result in serious disability and even death. The transmission of human diseases through food, water and waste water is a global problem, particularly in developing countries where gastrointestinal diseases are one of the most important causes of mobility and mortality. However, food habits adopted by populations may mitigate or increase the hazards ${ }^{3-4}$. The above mentioned hazards can be minimized to a great extent simply by monitoring the microbiological quality of food and drinks and creating awareness among the people about the fundamental principles of sanitation and hygienic quality of foods. The purpose of this study was to assess ready-to-eat foods and drinks consumed by people of different socioeconomic status.

The study was confined to Dhaka City where varieties of fast foods are consumed by different classes of people under various environments. It was a randomized cross sectional survey conducted in the Dhaka City. On the basis of consumers taste rating of foods and establishments and food price the four categories of shops were selected as Type A (upper class, $n=54$ ), Type B (middle class, $n=78$ ), Type $C$ (moderate class, $n=42$ ) and Type $D$ (lower class, $n=30$ ). Observation of hygienic status of the selected restaurants was followed with questionnaire technique.

About $200 \mathrm{~g}$ of solid or semi-solid and $200 \mathrm{ml}$ liquid samples were collected aseptically and were kept in insulated cool box. Solid or semi-solid food samples ( $20 \mathrm{~g}$ ) were mixed with sterile Ringer's solution and homogenized with stomacher for 5-10 and serial dilutions were made up to $10^{-8}$. The membrane filtration technique was followed for trapping the bacterial cells in liquid samples (e.g., drinks, water etc.). The trapped cells on the filter were then

\section{*Corresponding author:}

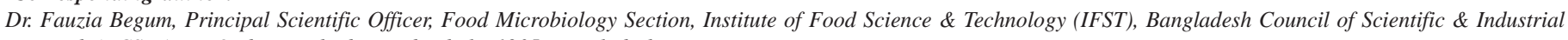
Research (BCSIR), Dr Qudrat-e-Khuda Road, Dhaka 1205, Bangladesh

Tel (Office): (02) 8614884; Cell: 01713015313 
placed directly on the appropriate solid medium for growth, except the trapped cells of soft drinks that were washed with the Ringer's solution to remove the preservatives. Bacteriological analyses were performed by standard method ${ }^{5-6}$. The microbiological condition of safety and hygiene were assayed using the methods recommended by ICMSF5 .

The quality of samples was assessed by determining standard plate count (SPC), total coliform count, thermophilic and psychrophilic counts and detecting the indicator microorganisms, Escherichia coli and Salmonella sp. Among the samples, about $78 \%$ Type A, $86 \%$ Type B, $100 \%$ Type C and $100 \%$ Type D gave mesophilic bacterial count $>10 / \mathrm{g}$, while the other samples especially the soft drinks showed bacterial counts $<10 /$ g. These indicate that the bacteriological status of meat-based ready-toeat foods served in Dhaka City is poor and that could be an important cause of food poisoning or food-borne infection ${ }^{7}$. Only $15 \%$ Type A samples was found to be seriously contaminated, while 23, 43 and 57\% of Type B, Type C and Type D foods and soft drinks respectively were found to be seriously contaminated (Table 1). The heights contamination (100\%) was obtained in Type $\mathrm{C}$ and Type D supplied water, followed by Type D potato chips (67\%). A few samples of patties, beef burger and egg pudding were found to be contaminated. Most of the samples of Type B,
Type C and Type D Singara and chicken patties were also found to be highly contaminated. On the other hand, the bacterial counts in chocolate milk, soft drinks and orange juice samples were within acceptable range and considered to be safe for consumption.

Overall, on the basis of SPC, about 85\% samples of Type A, 77\% samples of Type B, $57 \%$ samples of Type C and $43 \%$ samples of Type D fast foods and soft drinks were acceptable (Table 1). Among the total 204 samples of different varieties, about 70\% samples were acceptable for consumption, while $30 \%$ were contaminated and therefore unsafe for consumption. It was observed that Type A fast foods and soft drinks were comparatively safer than the others indicating that they were prepared under proper hygienic conditions. Considering safety and hygiene, microbiological risk was lowest in foods and drinks of Type A, followed by Type B, Type C and Type D. One survey indicates that the wrapped sandwiches showed sings of contamination during preparation and of growth of bacteria before vending ${ }^{8}$. Similar results were obtained by McCroan et al. ${ }^{9}$, who concluded that spiced-ham sandwiches are more hazardous than sandwiches containing mayonnaise, e.g., egg-salad and chickensalad sandwiches.

Considering total coliform count, $13-48 \%$ of different food categories was served as unhygienic conditions, and was unfit

Table 1. Frequency of seriously contaminated various types of fast foods and soft drinks

\begin{tabular}{|c|c|c|c|c|c|c|c|c|}
\hline \multirow[t]{2}{*}{ Food item } & \multicolumn{4}{|c|}{ No. of sample analyzed } & \multicolumn{4}{|c|}{ No. (\%) of sample seriously contaminated } \\
\hline & Type A & Type B & Type C & Type D & Type A & Type B & Type C & Type D \\
\hline \multicolumn{9}{|l|}{ Cereal-based } \\
\hline Singara & 6 & 6 & 6 & 6 & $0(0)$ & $1(17)$ & $1(17)$ & $2(33)$ \\
\hline Patties & 6 & 6 & 6 & 6 & $1(17)$ & $0(0)$ & $2(33)$ & $3(50)$ \\
\hline Bread & - & 6 & 6 & 6 & - & $2(33)$ & $2(33)$ & $2(33)$ \\
\hline \multicolumn{9}{|l|}{ Meat-based } \\
\hline Chicken patties & 6 & 6 & - & - & $0(0)$ & $1(17)$ & - & - \\
\hline Beef burger & 6 & 6 & 6 & - & $2(33)$ & $2(33)$ & $2(33)$ & - \\
\hline \multicolumn{9}{|l|}{ Egg-based } \\
\hline Egg Sandwich & 6 & 6 & - & - & $3(50)$ & $3(50)$ & - & - \\
\hline Egg pudding & 6 & 6 & - & - & $2(33)$ & $2(33)$ & - & - \\
\hline \multicolumn{9}{|l|}{ Vegetable-based } \\
\hline Potato chop & - & 6 & 6 & 6 & - & $3(50)$ & $2(33)$ & $4(67)$ \\
\hline Vegetable roll & - & 6 & 6 & - & - & $4(67)$ & $3(50)$ & - \\
\hline \multicolumn{9}{|l|}{ Milk-based } \\
\hline Chocolate milk & 6 & 6 & - & - & $0(0)$ & $0(0)$ & - & - \\
\hline Pasteurized & - & 6 & - & - & - & $0(0)$ & - & - \\
\hline \multicolumn{9}{|l|}{ Drinks } \\
\hline Cold drink & 6 & 6 & - & - & $0(0)$ & $0(0)$ & - & - \\
\hline Orange juice & 6 & 6 & - & - & $0(0)$ & $0(0)$ & - & - \\
\hline Supply water & - & - & 6 & 6 & - & - & $6(100)$ & $6(100)$ \\
\hline Total & 54 & 78 & 42 & 30 & $8(15)$ & $18(23)$ & $18(43)$ & $17(57)$ \\
\hline
\end{tabular}


for human consumption in $39,50,50$, and $46 \%$ of the Type A, Type B, Type C and Type D foods respectively. The psychrophilic bacteria were present in about 19, 19, 33 and $42 \%$ samples of Type A, Type B, Type C, Type D respectively, which not suitable for long-term preservation in refrigerated condition. Salmonella was detected in one sample of Type A, two samples each of Type B, Type C and Type D. A considerable number of samples of tested varieties contained Escherichia coli. Though food is the prime for energy without knowing it causing health hazard to the individual. Although there is no available epidemiological data about the risks of fast food-borne diseases resulting from these food supply and drinking water in Bangladesh, sparse information about the risk of street-vended foods in other developing countries has been published ${ }^{10}$. Laboratory evidence shows that risk of spreading agents of food-borne disease via street-vended foods can be high or that such foods frequently have high microbial counts ${ }^{11}$.

The hygienic status of different types of restaurants is shown in Table 2. Personal hygienic status was very poor in case of Type D restaurants (94.0\%) and Type C (85.2\%), while it was very good in Type A restaurant (95.0\%). The storage condition of Type D (99.0\%), Type C (94.0\%) and Type B (60.5\%) restaurants was also very poor. It was not also very satisfactory in case of Type A restaurants. The environment of Type A (89.7\%) and Type B (62.5\%) were comparatively better though they were not very satisfactory. In case of Type D (97.0\%), the environmental condition was very dangerous and almost no restaurant of this category was found to be safe. Educational status of servers was very good in case of Type A (98.0\%) restaurants. Servers of almost all of the Type D (100.0\%) and Type C (84.0\%) restaurants were found to be illiterate. It may be said that the hygienic status of Type $C$ and Type $D$ restaurants was very dangerous, while Type A and Type B restaurants was comparatively better though not at expected satisfactory level. The environmental significant effects on the risk of microbiological contamination have been reported ${ }^{12}$. Practices of inadequate hygienic measures, mishandling, in proper storage, inadequate cooking and above all unhygienic condition of the retail shops are responsible for food-borne outbreaks ${ }^{13-15}$. Also, the implication of food handler in food-borne disease is observed in different studies by Hall and Hauser ${ }^{16}$.

Table 2. Hygienic status of different types of restaurants and other food establishments

\begin{tabular}{lcccc}
\hline Factor & \multicolumn{3}{c}{$\begin{array}{c}\text { Good hygienic condition of various } \\
\text { sources of food (\% ) }\end{array}$} \\
\cline { 2 - 5 } & Type A & Type B & Type C & Type D \\
\hline Personal status of servers & 95.0 & 68.0 & 14.8 & 6.0 \\
Status of storage conditions & 81.0 & 39.5 & 6.0 & 1.0 \\
Condition of food environment & 89.0 & 62.5 & 26.0 & 3.0 \\
Status of interior environment & 89.5 & 72.0 & 19.5 & 0.0 \\
Educational status of servers & 98.0 & 43.0 & 16.0 & 0.0 \\
Sources of drinking water & 100.0 & 75.0 & 56.0 & 12.0 \\
\hline
\end{tabular}

In conclusion, it can be said that most of the fast foods of the city restaurants are contaminated with huge load of microorganisms, especially in Type C and Type D categories. Type A and Type B fast foods are relatively safer, but some of these foods are seriously contaminated and not safe to eat. People in Dhaka City are taking contaminated foods with or without their knowledge. Most outbreaks are generally caused by foods that have been mishandled or mistreated during preparation or storage. It is, therefore, essential for people who handle the foods to be properly trained on safe food handling under special care by the concerned enterprises and the governmental authorities. Lack of knowledge in safe food by the owners and servers of the restaurants promote the food contamination process unconsciously.

\section{References}

1. LeBaron CW, Furutan NP, Lew JF, Allen JR, Gouvea V, Moe C, et al. 1990. Viral agents of gastroenteritis. Morb Mortal Wkly Rep. 39(RR-5): $1-24$.

2. CDC. 1990. Foodborne hepatitis A - Alaska, Florida, North Carolina, Washington. Morb Mortal Wkly Rep. 39(14): 228-232.

3. WHO. 1968. Microbiology aspects of food hygiene. Technical Report, Series No. 399. World Health Organization (WHO), Geneva.

4. WHO. 1976. Microbiological aspects of food hygiene. Technical Report, Series No. 598. World Health Organization (WHO), Geneva.

5. ICMSF. 1978. Microorganisms in Food 2: Sampling for Microbiological Analysis. Principles and Specific Applications. International Commission on Microbiological Specifications for Foods (ICMSF). Chapman \& Hall, London.

6. Thatcher FS \& Clark DS. 1968. Microorganisms in Food. I. Their Significance and Methods of Enumeration. University of Toronto Press, Toronto.

7. Begum F, Banana UH, Sultana DA, Rao ER \& Varadaraj MC. 2004. Bacteriological status of some meat-based ready-to-eat foods served in Dhaka City. Bangladesh J Microbiol. 21(2): 62-64.

8. Adame JL, Post FJ \& Bliss AH. 1960. Preliminary report on a bacteriological study of selected commercially prepared wrapped sandwiches. J Milk Food Technol. 23: 363-366.

9. McCroan JE, McMinley TW, Brim A \& Henning WC. 1964. Staphylococci and salmonellae in commercially wrapped sandwiches. Public Health Rep. 79: 997-1004.

10. Sami Z \& Bari A. 1986. Food hygiene with reference to public health. Viable bacterial counts of ready to eat foods served in Rawalpindi, Islamabad. J Pak Med Assoc. 36: 304-307.

11. CDC. 1991. Update: Cholera - Western Hemisphere, and recommendations for treatment of cholera. Morb Mortal Wkly Rep. 40(32): 562-565.

12. FAO/WHO. 1974. Food-borne disease: Methods of sampling and examination in surveillance programmes. Technical Report, Series No. 543. World Health Organization (WHO), Geneva.

13. Bean NH, Goulding JS, Lao C \& Angulo FJ. 1996. Surveillance of foodborne-disease outbreaks - United States, 1988-1992. Morb Mortal Wkly Rep. 45(SS-5): 1-55.

14. Paulson DS. 1994. A comparative evaluation of different hand cleansers. Dairy Food Environ Sanit. 14: 524-528.

15. Restaino L \& Wind CE. 1990. Antimicrobial effectiveness of hand washing for food establishments. Dairy Food Environ Sanit. 10: 136141 .

16. Hall HE \& Hauser GH. 1966. Examination of faeces from food handlers Salmonella, Shigella, enteropathogenic Escherichia coli and Clostridium perfringens. Appl Microbiol. 14: 928-933. 